\title{
ESTUDO DAS PROTEÍNAS SÉRICAS NA BLASTOMICOSE SUL-AMERICANA
}

\author{
A. M. Fiorillo $*:$, L. Takaoka $* *:$ e L. A. R. Fernandes $* * * *$
}

Os autores estudaram o quadro serico protéico de sete pacientes com Blastomicose Sul-Americana, utilizando a eletroforese em papel, a separaçāo cromatográfica em coluna de Sephadex G-200 e a imunoeletroforese em agar. Os pacientes apresentavam lesōes pulmonares, com ou sem adenopatia, ou apenas adenopatia localizada ou generalizada e esta acompanhada ou não de lesões do tubo gastro-intestinal, reveladas pelo $R x$.

Chegaram à conclusão de que a Blastomicose determina elevação do teor das imunoglobulinas do tipo $\operatorname{Ig} G$ e $\operatorname{Ig} M$ e não do IgA. Sugerem que as imunoglobulinas do tipo $\mathrm{IgG}$ se elevam com a formaçāo de granulomas e reparaçāo fibrótica, além de refletirem a resposta imune especifica do processo em fase crônica, enquanto que as do tipo IgM aumentam de teor na fase aguda ou de agudizaçāo da doença. quando os fenómenos de exsudaçî́o e necrose se tornam berm evidentes.

\section{INTRODUÇĀO}

Estudos iniciais, pormenorizados, das proteinas do soro na Blastomicose SulAmericana foram realizados por Del Negro e Fiorillo, em 1954 (2). Verificaçōes relacionadas a muco-proteinas e anticorpos específicos foram feitas por Fava Netto, Ferri e Lacaz em 1959 (5). Barbosa, em sua tese de 1968 (1), re-estudou o quadro protéico em um número grande de pacientes, utilizando-se da separação eletroforética em papel. As alteraçōes encontradas pelos autores mais recentes não trouxeram esclarecimentos maiores quanto ao com- portamento das imunoglobulinas do sistema gama ( $\operatorname{IgG}, \operatorname{IgA}$ e $\operatorname{Ig} M$ ), nas diferentes fases de evolução dessa doença. Utilizancio uma metodologia mais delicada, procuramos estudar as modificaçōes dessas globulinas em diferentes modalidades clínicas da Blastomicose.

\section{MATERIAL E MÉTODOS}

O estudo preliminar consta de achados correspondentes a sete de nossos pacientes com Blastomicose Sul-Americana, internados no Serviço de Moléstias Infecciosas da Faculdade de Medicina de Ri-

Trabaiho do Departamento de Clintca Medice da Faculdade de Medicina de Ribeirâo Preto iServico de Doenças Infecciosas e Tropicais।

* Professor Adjunto do Departamento de Clinica Médica da F.M.R.P. (Chefe do Serviç)

*** Residente de Cinica Medica.

** Auxiliar de Ensino do Departamento de Clinica Médica da F.M.R.P.

Recebido para publicação em 25.5 .1972 
beirão Preto. Os doentes foram escolhidos de maneira a apresentarem quadros clínicos variáveis, para que pudéssemos correlacionar as alteraçooes das globulinas com as várias modalidades de patologia. o diagnóstico foi comprovado pelo achado do parasito em material de biopsia ou em produtos patológicos como escarro ou secreção de gânglios fistulizados ou abcedados. Foram realizados também exames complementares numerosos, incluindo os radiológicos, a fim de caracterizarmos os diferentes aspectos clínicos ou, então, excluir doenças concomitantes que pudessem interferir em nossas conclusões.

Estudo das proteinas séricas. Para o estudo das proteinas executamos a dosagem do teor total, a separação pela eletroforese em papel, a imunoeletroforese em agar e a separação em coluna de Sephaciex G-200. Os valores normais correspondem aos obtidos de 10 indivíduos sadios.

Dosagem das proteinas totais. As proteínas totais do sôro e das fraçōes separadas em coluna foram dosadas pelo micrométodo do biureto de Lowry (6).

Separaçío das imunoglobulinas. As imunoglobulinas foram separadas em coluna de Sephadex G-200* de acorcio com o método de Fahey e Terry (4) modificado. A coluna tinha as dimensōes de $2,5 \times 80,0 \mathrm{~cm}$; a eluição foi executada NaCl-0,3 M. As fraçōes, em volume de $5,9 \mathrm{ml}$, foram recolhidas em coletor automático e a distribuição das proteínas no eluato foi determinada com o auxilio de espectrofotômetro **, a $280 \mathrm{~m}_{\text {is. }}$. As curvas de densidacie otica têm as caracteristicas apresentadas nas figs. de 1 a 7 . Foram feitos "pools" das fraçoes $P_{1}, P_{., 2}, P_{: 3}$, $\mathrm{P}_{+}$e $\mathrm{P}_{\bar{n}}$, conforme indicação das figuras citadas.

Identificação das fraçōes. As fraçōes citadas acima foram concentradas por pervaporação no vácuo, antes de serem identificadas. A identificação dos componentes de cada fração separacia pelo Sephadex foi realizada através da imunoeletroforese em agar pelo micro-método de Scheideger (7), utilizando-se anti-soros específicos anti IgA e IgM de procedência holandesa ***.

\footnotetext{
* Sephadex G-200. Pharmacia-Uppsala. Sweden. * Espectrofotometro Gilford - Modelo 240.

** Central Laboratorium Van de Bloed transfusiedient. Amsterdam.
}

As fraçóes separadas pelo Sephadex G-200 mostraram, como componentes predominantes, as globulinas IgG no "pool" 2 e as globulinas IgM no "pool" I (Figs. 8,9 e 10 l.

\section{RESULTADOS}

Os resultados globais, obtidos pela separaçào eletroforética em papel e pela coluna de Sephadex estão lançados na $\mathrm{Ta}$ bela I. O instantâneo clínico e protéico correspondente a cada paciente, em época oportuna, está registracio nos Quadros de 1 a 7.

O paciente O.C.G. (Quadro 1) apresentava doença ganglionar, com infartamento cervical e abdominal, mas sem manifestaçōes clínicas para o lado do aparelho digestivo e pulmão. O estudo protéico revelou aumento de globulinas $\gamma$; a imunoeletrcforese e separação pelo Sephadex demonstraram que as $\gamma$ globulinas aumentadas eram do tipo IgG. Clinicamente, o paciente apresentava doença não generaiizada.

O paciente D.F.L. (Quadro 2) apresentava alterações pulmonares de tipo fibrótico e lesōes cutäneas pouco intensas e extensas; clinicamente podemos classificá-lo como doente em fase crônica. A análise protéica demonstrou aumento de globulinas a 2 e discreta elevação do teor das $y$ globulinas, de tipo IgG.

O paciente O.C. (Quadro 3) apresentava alterações pulmonares de tipo residual, fibrótico e micro-adenopatia cervical. O estudo protéico revelou discreto aumento de globulinas a 2 e $\gamma$, com elevação da fraçāo IgG.

O paciente L.D.B. (Quadro 4) apresentava adenopatia generalizada, inclusive de abdome, alteraçōes pronunciadas do tubo digestivo, e esplenomegalia, indicando cioença em fase ativa, de exsudação. o quadro protéico revelou aumento das globulinas a 2 e $\gamma$; o aumento de $\gamma$ correspondia à elevação das globulinas IgG e $\operatorname{Ig} \mathrm{M}$.

O paciente A.F. (Quadro 5) era portador de adenopatia generalizada, periférica e abdominal, de alterações da mucosa intestinal (jejuno e íleo) e discreta esplenomegalia. No total, seu aspecto clínico era semelhante ao do paciente anterior. o quadro protéico revelou aumento das 


\section{TABELA I}

Teor protéico, em mg\%, das fraçòes separacias por eletroforese em papel e por coluna de Sephadex G-200. Os valores normais para o Sephadex correspondem às médias obtidas de 10 indivíduos.

\section{ELETROFORESE}

\begin{tabular}{|c|c|c|c|c|c|c|c|c|c|c|}
\hline \multirow{2}{*}{ Nome } & & & $\ldots \ldots$ & & & \\
\hline & A & a 1 & $\alpha 2$ & $\beta$ & $\gamma$ & $P_{1}$ & $P_{. z}$ & $P_{: 3}$ & $P_{1}$ & $P_{j}$ \\
\hline O.C.G. & 2410 & 430 & 690 & 600 & 4470 & 201 & 2588 & 3927 & 1127 & 703 \\
\hline D.F.L. & 3280 & 340 & 1340 & 920 & 2520 & 488 & 2769 & 2359 & 1399 & 1384 \\
\hline O.C. & 3320 & 410 & 970 & 810 & 2590 & 480 & 3060 & 1016 & 1505 & 2037 \\
\hline L.D.B. & 2380 & 820 & 1100 & 660 & 3280 & 612 & 1924 & 193 & 950 & 2491 \\
\hline A.F. & 2410 & 420 & 1250 & 750 & 3500 & 791 & 2410 & 1255 & 742 & 3346 \\
\hline M.I.A.C. & 2400 & 560 & 800 & 720 & 3520 & 820 & 3009 & 1595 & 1388 & 2400 \\
\hline W.S. & 3540 & 630 & 1000 & 1500 & 2820 & 1124 & 2326 & 1096 & 1083 & 1266 \\
\hline Normal & 3500 & 200 & 300 & 600 & 1000 & & & & & \\
\hline & 5200 & 500 & 800 & 1000 & 1800 & 361 & 1310 & 778 & 753 & 2903 \\
\hline
\end{tabular}

SEPHADEX G-200 globulinas a 2 e $\gamma$; destas, a elevaçāo corresponciia a das IgG e IgM.

O paciente M.I.A.C. (Quadro 6) apresentava adenopatia cervical e lesōes cutâneas úlcero-vegetantes, extensas e intensas, além de esplenomegalia. Não apresentava, ao $\mathrm{Rx}$. lesões pulmonares ou intestinais. O quadro protéico mostrou aumento das globulinas $\%$; destas, a elevação correspondia ao aumento das IgG e IgM.

O paciente W.S. (Quadro 7) apresentava alteraçōes evidentes da mucosa intestinal e calcificação de gânglios mesentéricos ao $\mathrm{Rx}$; além disso, adenopatia cervical exuberante. O quadro proteico revelou aumento de a 2 e $\gamma$ globulinas; destas, a elevaçāo correspondia a das IgG e IgM.

\section{DISCUSSÃO}

No quaciro histopatológico da Blastomicose Sul-Americana encontramos exsudatos inflamatórios, necroses e reparaçāo fibrótica; a morfologia da lesāo primária é a do granuloma, com os parasitos em seu interior. O componente exsudativonecrótico tem correspondente, no quadro sérico protéico, no elevado teor de muco- proteínas (5), no aumento da velocidade de hemossedimentação $(1,3,5)$ e na elevaçāo das a 2 globulinas, pois cerca de $60 \%$ da composição destas são constituidas de glicoproteínas $(2,3)$.

O estímulo do mesênquima, com formação cie granulomas, determina modificações no teor das $\gamma$ globulinas séricas. A formação de anticorpos específicos, de tipo IgG e IgA elevam os valores das imunoglobulinas correspondentes do soro; globulinas de tipo IgG poderiam representar anticorpos especíiicos, 7S, ou para-proteínas; globulinas de tipo IgM representariam anticorpos 19S, ou para-proteínas. Os achados de nossos pacientes, correlacionados com o exame clínico e com os exames complementares de laboratório, demonstraram que as alteraçōes de tipo exsudativo-necrótico, principalmente ganglionar, determinam elevaçāo do teor das a 2 globulinas. Por outro lado, a elevação cias $\gamma$ globulinas corresponde à atividade granulomatosa e à atividade imunogênica especifica. Trabalhos em andamento procuram esclarecer que papel têm os anticorpos específicos, nas variaçōes do teor das imunoglobulinas IgG, IgA e IgM, nas várias modalidades clinicas e em diferentes fases de atividade dessa doença. 


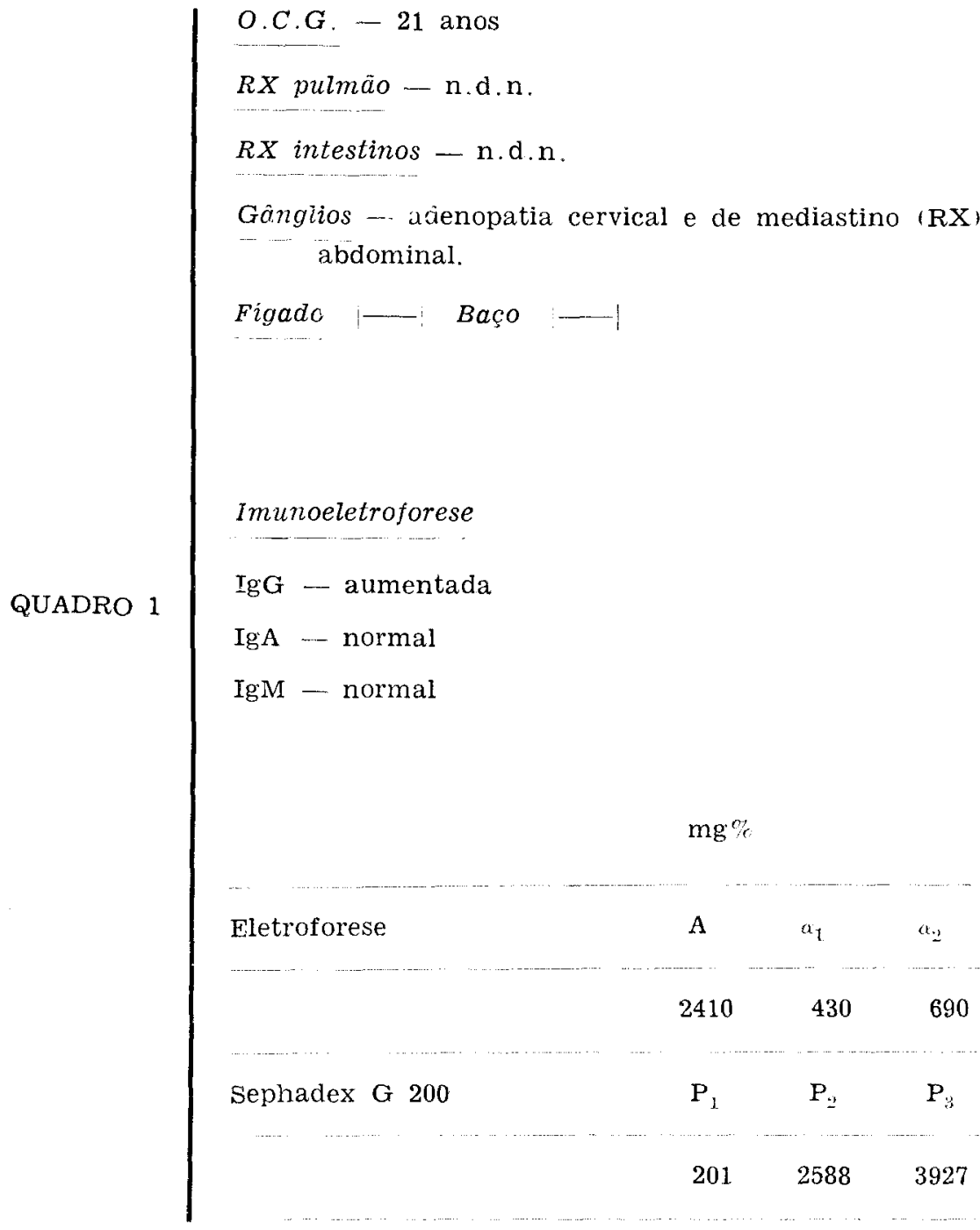




\section{adenopatia}
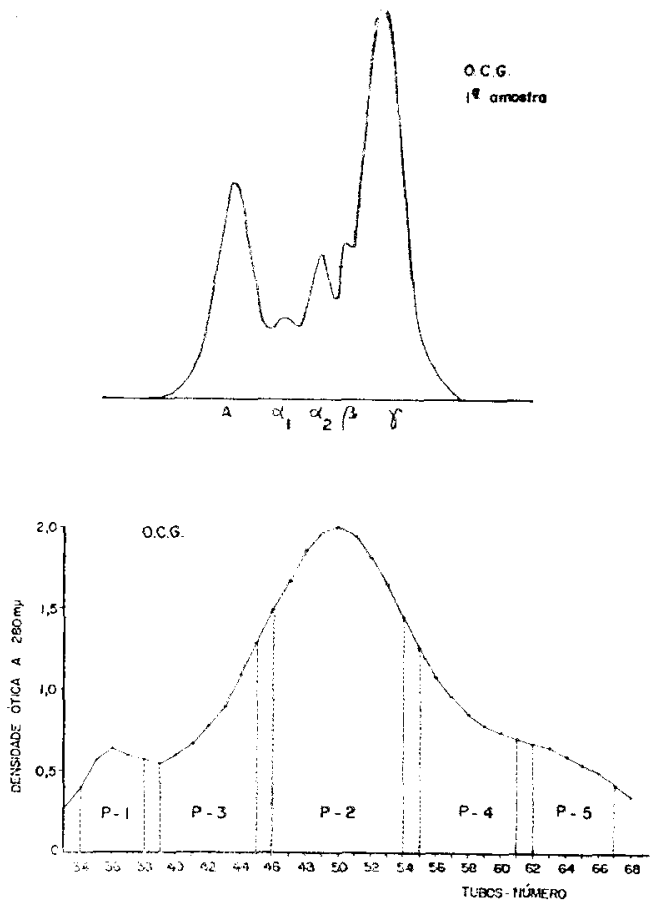

$600 \quad 4470$

Fig. 1 - Separação das proteinas do soro por eletroforese em papel (superior) e em Sephadex inferior:

$\mathbf{P}_{+} \quad \mathbf{P}_{-}$ 

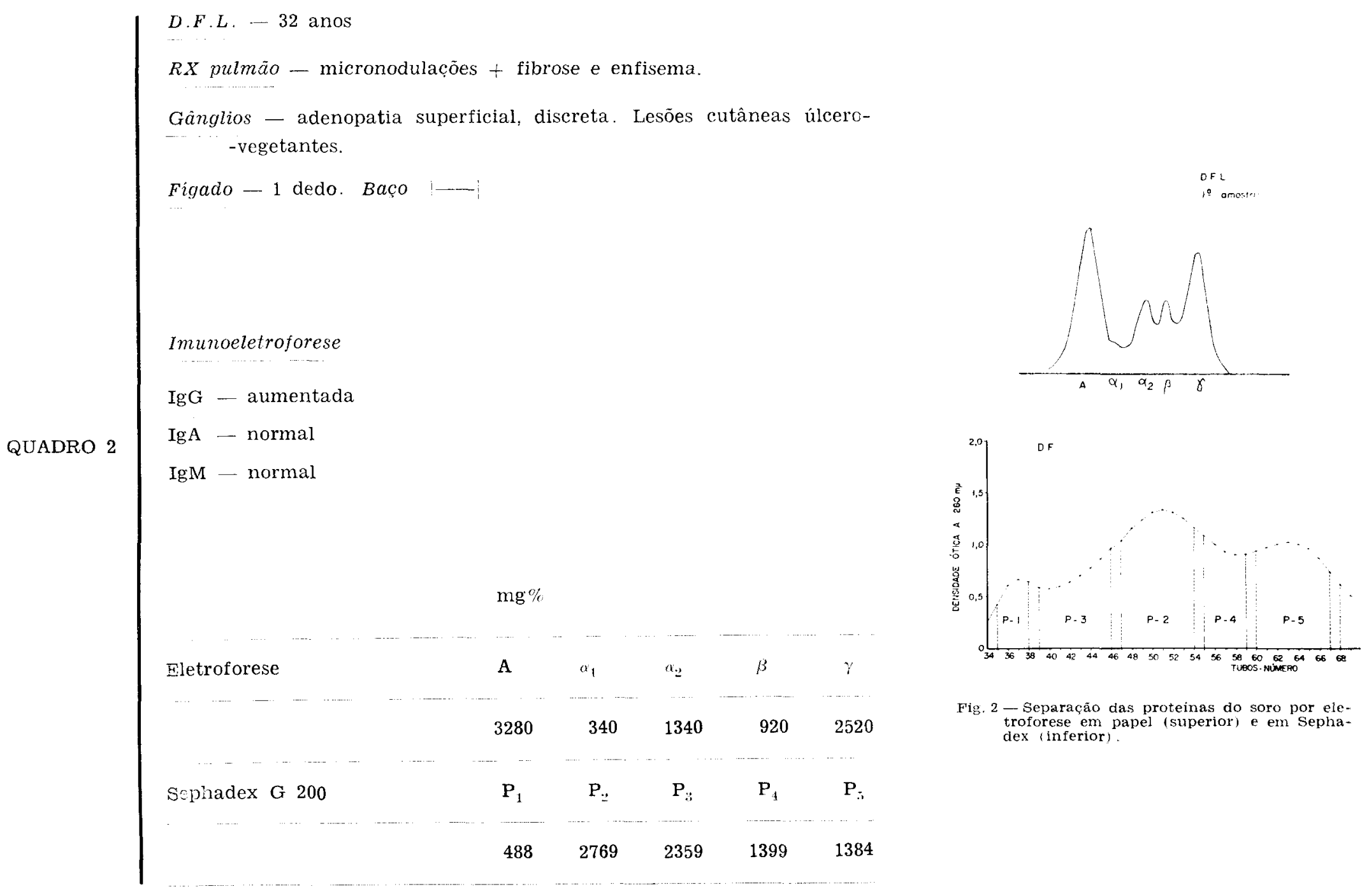

Fig. 2 - Separação das proteinas do soro por eletroforese em papel (superior) e em Sephadex (inferior). 


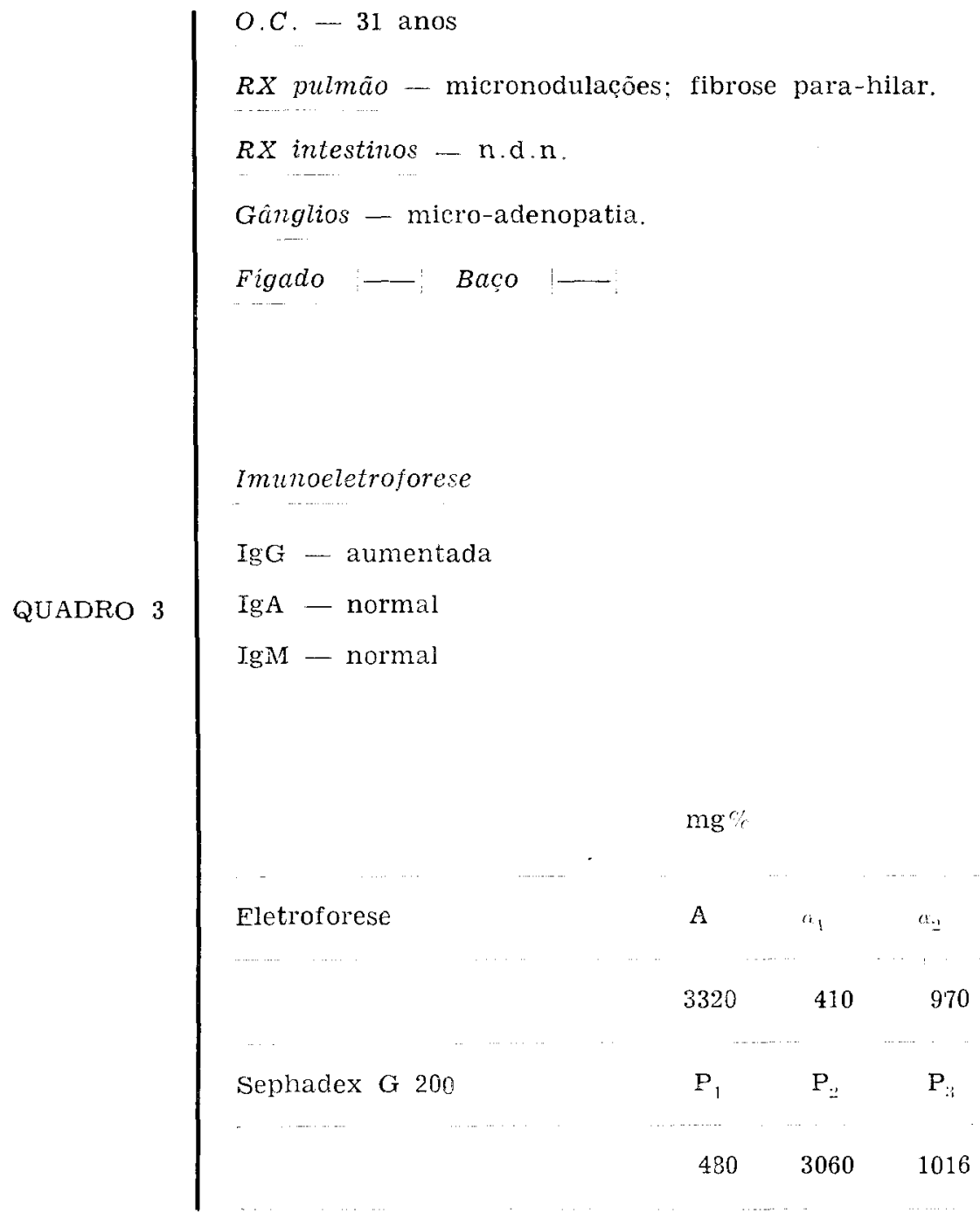




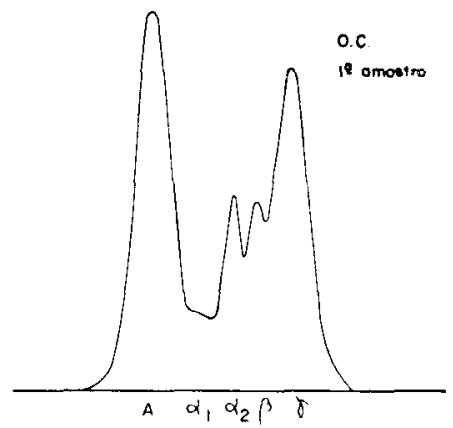

$b^{3} \quad a^{\prime}$

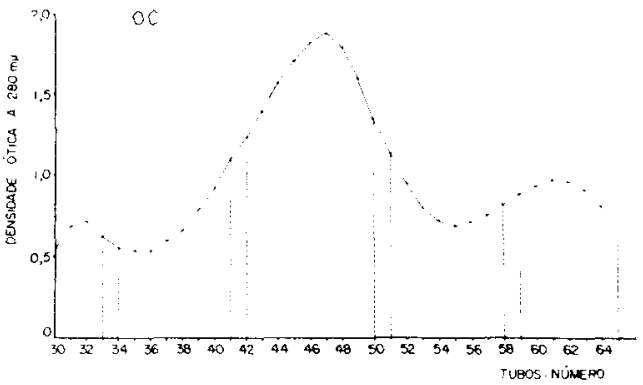

$810 \quad 25 \subseteq 0$

Fig. 3 - Separação das proteinas do soro por eletroforese em papel (superior) e en Sephadex (inferior).

$P_{+} \quad P_{-}$

$1505 \quad 2037$ 

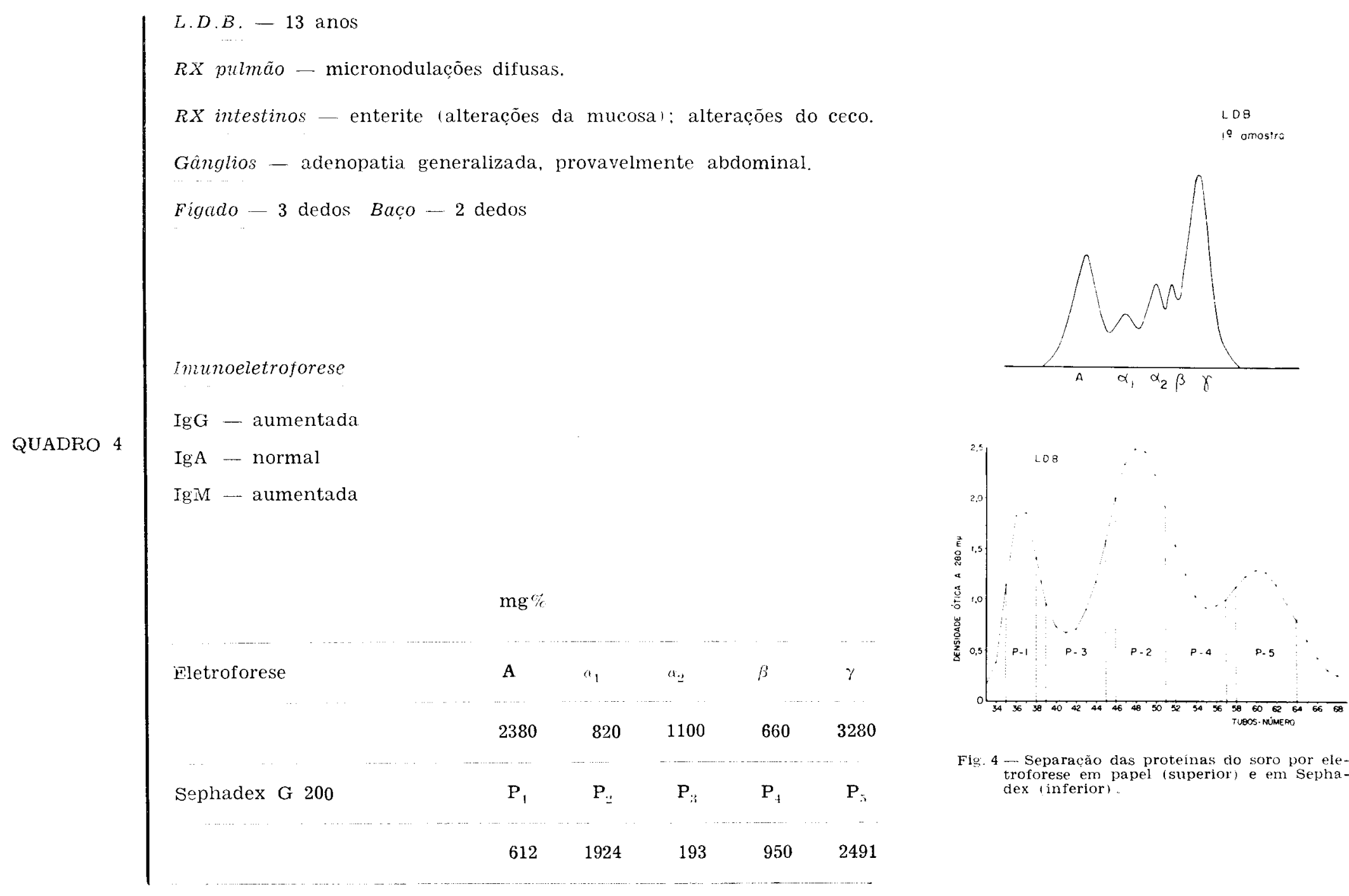

Fig. 4 - Separação das proteinas do soro por eletroforese em papel (superior) e em Sephadex linfer 


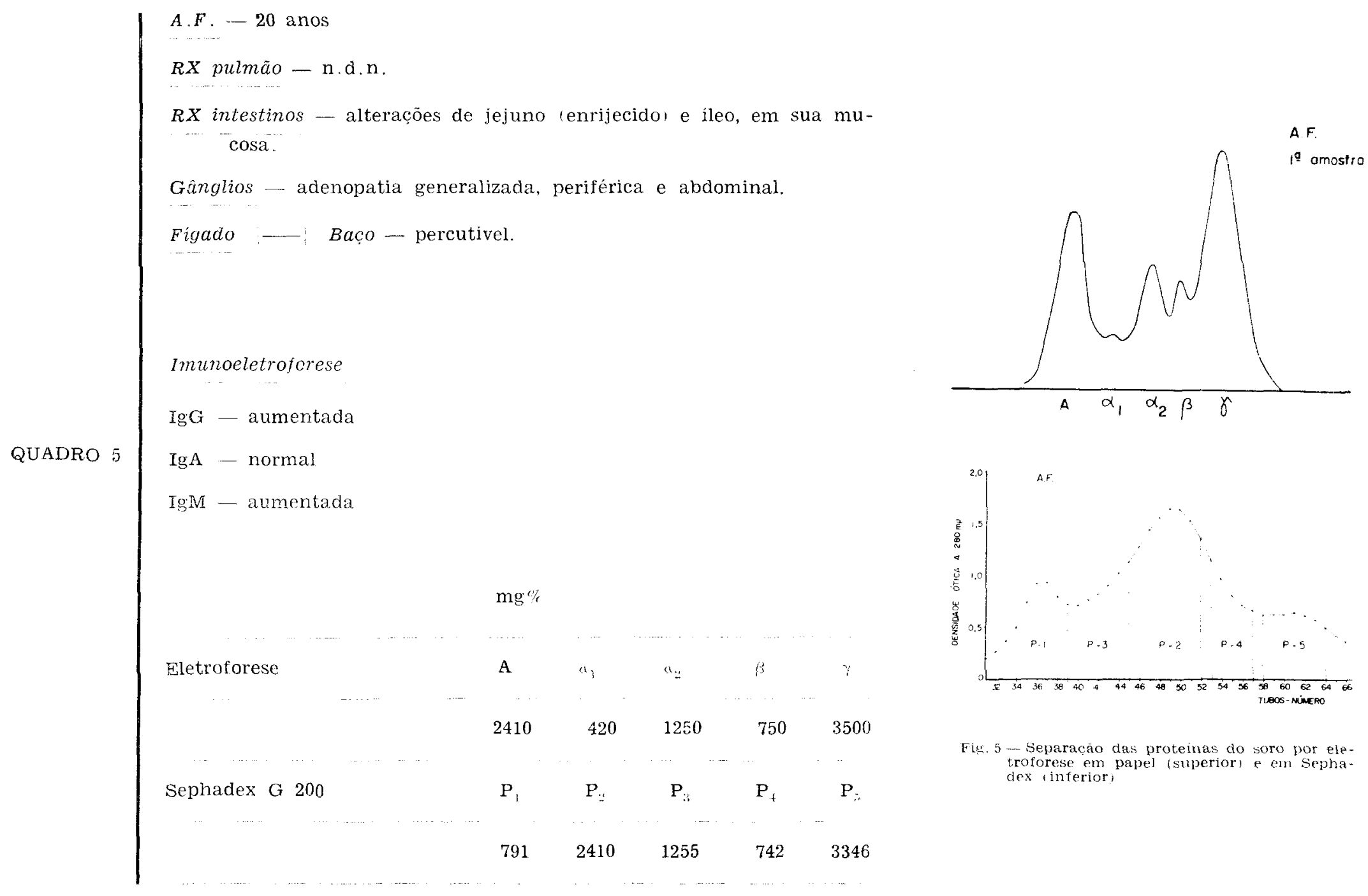




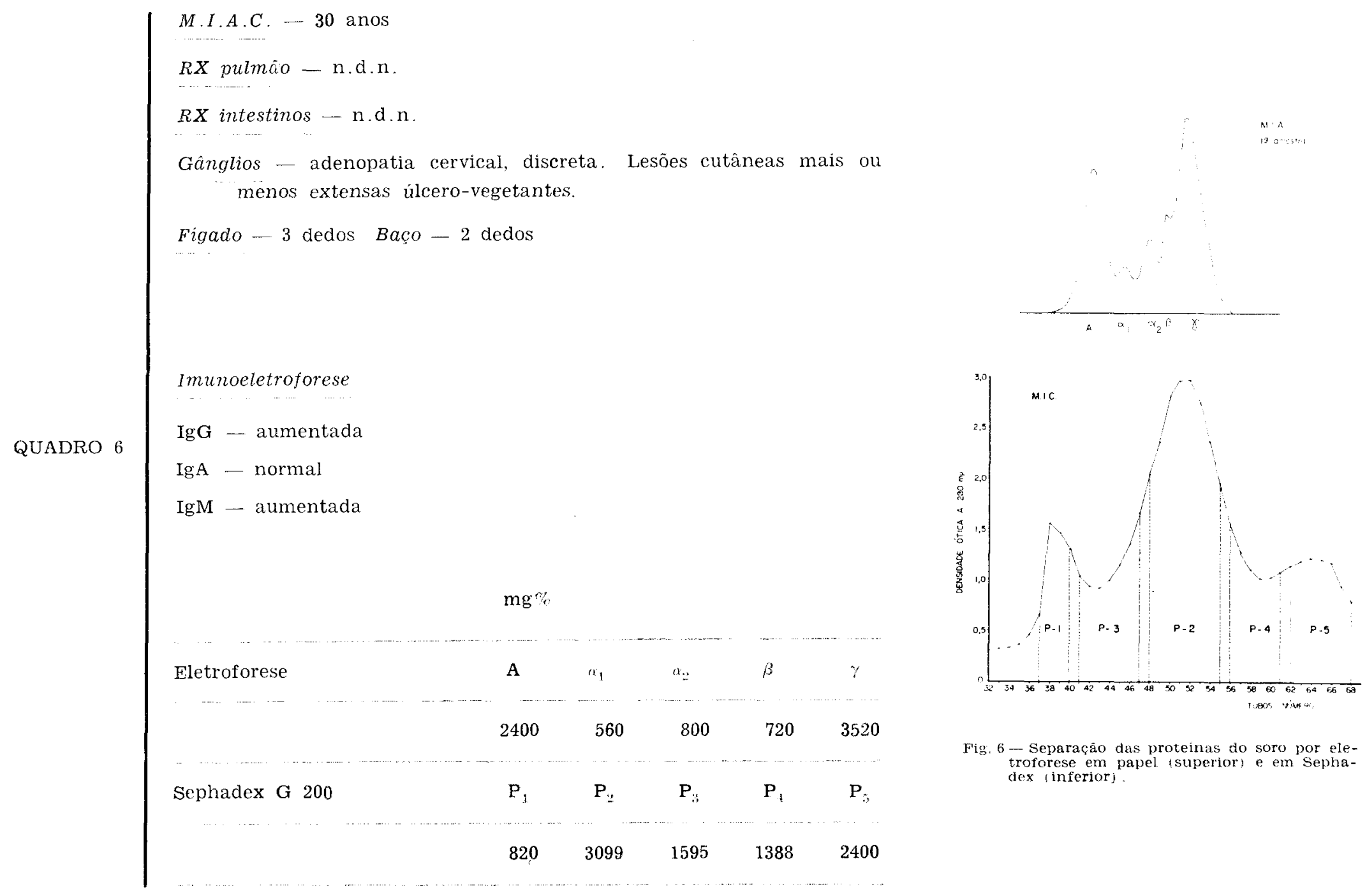



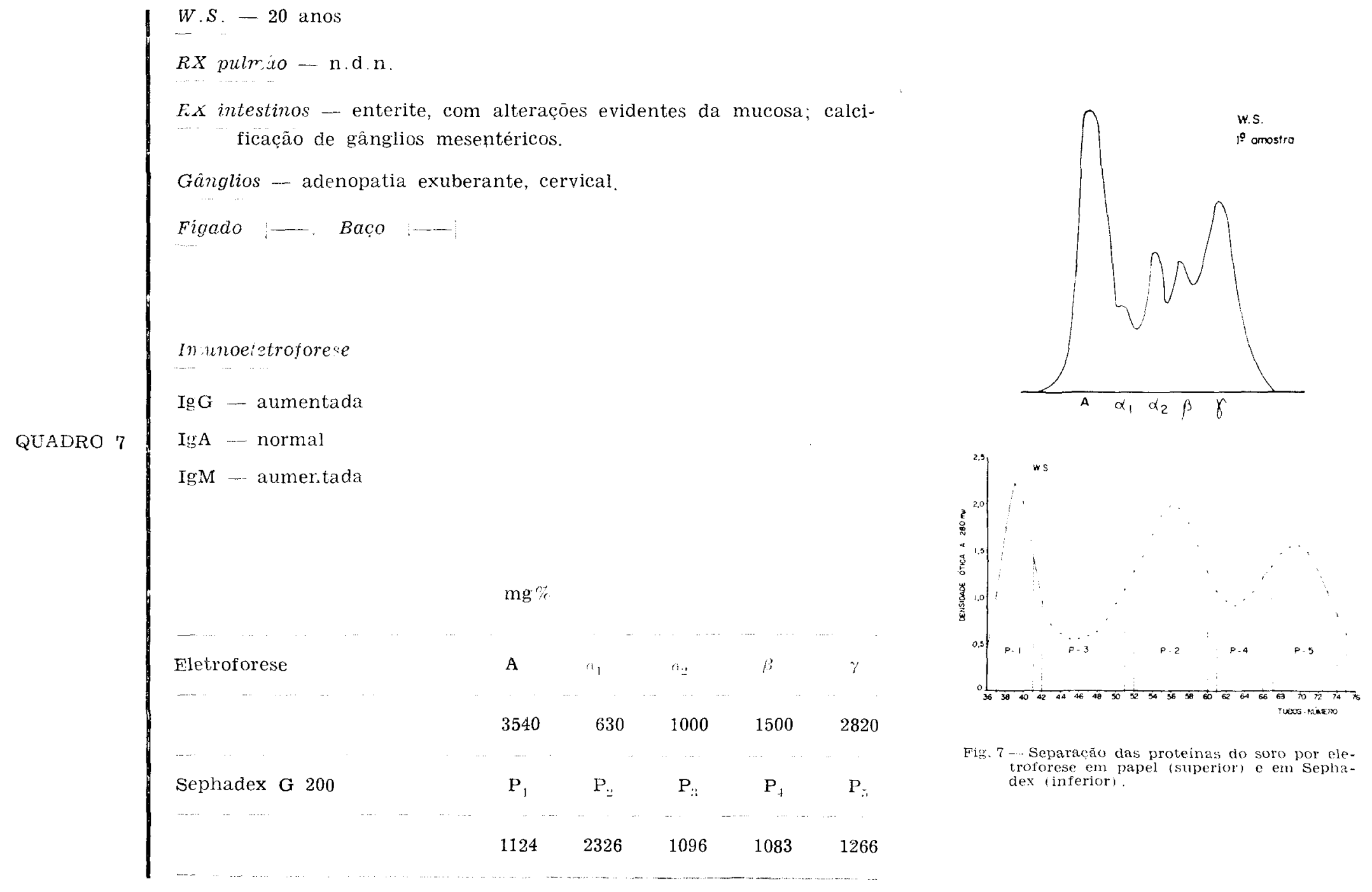

Fig. 7 -... Separaça áo das proteinas do soro por eletroforese em papel (superior) e em Sephadex (inferior). 


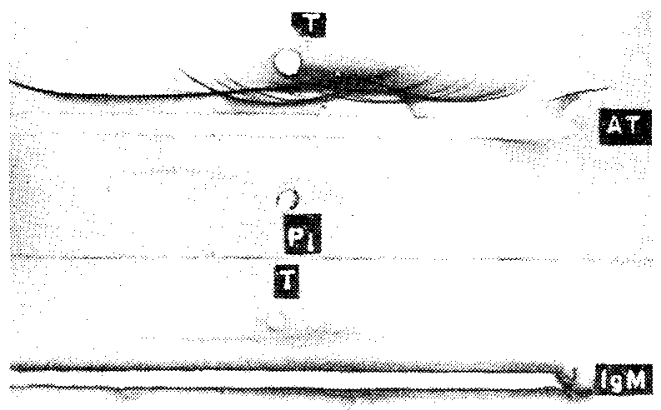

(2)

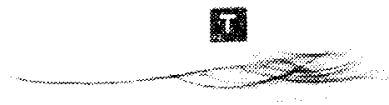

政

(6x)

DII

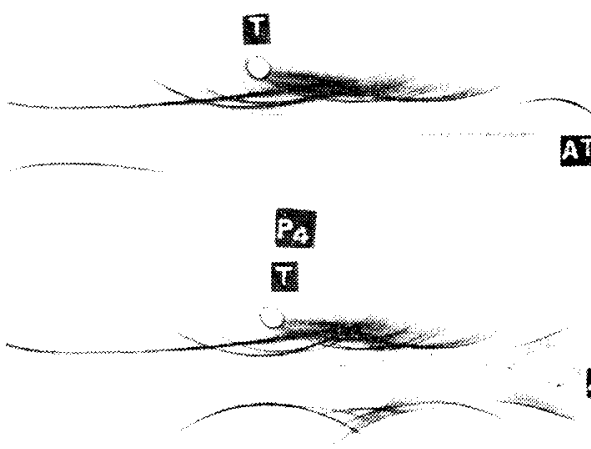

Fig. 8 - Imunoeletroforese do soro total i $\mathrm{T}$, e do Pool-l com soro anti-total (AT) anti IgM e anti Ig A. Presença de IgM e tu macroglobulinas e auséncia de IgA.

11.

5

AT

3

II

\section{Ea}

\section{0}

Fig. 9- Imunoeletroforese do soro total $|\mathrm{T}\rangle$ do Pool-2. com soro anti-total (AT) e anti IgA. Presença de IgG, IgA e tracos de a e $\beta$ globulinas.
Fig. 10 - Imumoeletroforese do soro total (T) e dos Pools 3, 4 e 5, com soro anti-total (AT) Presença de globulinas a em $P_{:, \cdot}$ de IgG. a e esboço de albumina em $P_{f}$ e de albumina, $\alpha$ e $\beta$ globulinas em $\stackrel{+}{P_{*}}$. 


\section{SUMMARY}

The authors emplcyed serum paper electrophoresis, immunoelectrophoresis in agar and fractionation on Sephadex G-200 column, to study the serum proteins in 7 patients with South American blastomycosis. Some patients had pulmonary lesions which were associated or not with enlargement of lymph nodes, others presented localizated or generalized enlargement of lymph nodes. In these patients with generalized enlargement of lymph nodes, they found or not lesions of intestinal tract demonstrated through $X$-ray. They conclude that immunoglobulins $G$ and $M$ are increased in Sout American blastomycosis.

The authors suggest that immunoglobulin $G$ is increased whether by chronic granulomatous infection or when this disease progress to fibrosis; it is also related with specific immune response. An increase in immunoglobulin $M$ in the acute phase or recurrence of the disease is demonstrated when there are necrosis or exsudation.

\section{REFERENCIAS BIBLIOGRAFICAS}

1. BARBOSA, W. - Blastomicose SuIAmericana. Contribuição ao seu estudo no Estado de Goiás. Tese de Docência-Livre. Faculdade de Medicina da Universidade Fecieral de Goiás, 1868

2. DEL NEGRO, G. \& FIORILLO, A. M. - O diagrama eletroforético na blastomicose sul-americana (nota prévia) Rev. Paul. Med., 45: 146, 1954.

3. DEL NEGRO, G. - Contribuição para o estudo clínico da blastomicose sulamericana (Doença de Lutz-Splendore-Almeida). Premmio Carlos Chagas. Acad. Nac. Med. 1955

4. FAHEY, J. L, \& TERRY, E. W. Ion exchange chromatography and gel filtration. In Weir, D. M. - Handbook of Experimental Immunology, Blackwell, Oxford, 1967.
5. FAVA NETTO, C., FERRI, R, G, \& LACAZ, C. S. - Poteinograma e algumas "provas da fase agucia do soro" na Blastomicose sul-americana. Estudo comparativo com as reacōes de fixação de complemento e de precipitacäo. Med. Cir. Farm. 277: 157. 1959

6. LOWRY, O, H., ROSENBROUGH, N. J., FARR, A. L. \& RANDALL, R. J. - Protein measurement with the Folin phenol reagent. J. Biol. Chem. 193: 265,1951 .

7. SCHEIDEGER, J. J. - Une microméthode de l'immuno-électrophorèse. Internat. Arch. Allergy \& Appl, Immunology, 7: 103, 1955 .

8. SCHMIDT, B. J. \& HOXTER, G. Estudos eletroforéticos em 16 casos de blastomicose sul-americana. Rev. Paul. Med, 55: 434, 1959 . 